\title{
VEGETATION COVER CHANGES AND CORRELATION WITH SUSPENDED SOLIDS CONCENTRATION OF STREAM WATER IN SMALL-SCALE FORESTED CATCHMENT
}

\author{
Baolin $\mathrm{SU}^{1}$, So KAZAMA ${ }^{2}$, Masaki SAWAMOTO \\ ${ }^{1}$ Student member of JSCE, Dept. of Civil Eng., Tohoku University \\ ${ }^{2}$ Member of JSCE, Dr. Eng., Associate Professor, Dept. of Civil Eng., Tohoku University \\ ${ }^{3}$ Fellow of JSCE, Dr. Eng., Professor, Dept. of Civil Eng., Tohoku University \\ (Aoba-yama 06, Sendai, 980-8579, Japan)
}

\begin{abstract}
The TM-based Normalized Difference Vegetation Index (NDVI) data set for each month of a year was made in the Kamafusa Lake catchment by using of 11 Landsat Thematic Mapper imagery and one image-based atmospheric correction algorithm-COST method. It showed more precise variation compared with the present NOAA/AVHRR-based 1-km NDVI data set, and is practically possible to detect the vegetation cover changes in small basin area by using of high resolution TM data. The attempts to apply this data set in analysis of vegetation cover changes and their effects on suspended solids of stream water were conducted. It showed that SS concentration was correlated with the vegetation cover changes to some extent. The study also showed that two different mechanisms, i.e., snowmelt process and rainfall-runoff process, should be considered for different season when incorporating the NDVI values to analyze the stream water quality variation
\end{abstract}

Key Words: Vegetation Cover, NDVI, Stream Water, Suspended Solids, Forest Cachment

\section{INTRODUCTION}

Vegetation covers, such as paddy field, cropland and forest coverage, usually affects and dominates the stream water quality of some agriculturalforested catchments. One tough and interesting research topic is to correlate the water quality changes, which due to non-point source pollution, with vegetation cover changes. As a popular vegetation cover index, Normalized Difference Vegetation Index (NDVI) is usually used to count the vegetation cover changes in a large scale area, like the global land cover database ${ }^{12) 3}$, which is made from $1-\mathrm{km}$ resolution NOAA/AVHRR imagery. Because the Kamafusa Lake catchment is very small, which has catchment area of nearly to 200 square kilometers, such ready but coarse resolution data set is not suitable to this purpose. Landsat Thematic Mapper (TM) imagery with ground resolution of 30 meters is an alternative data source for vegetation change detection.

The study area (Fig. 1) is the Kamafusa Dam catchment. The Kamafusa Lake plays an important role in the water supply because it is one of main drinking water supply sources of the Sendai City, Miyagi Prefecture of Japan. This catchment is a typical forested catchment, which includes about $82 \%, 11 \%$ and $2 \%$ of forest, agricultural area and residential area, respectively. In this catchment, there are three tributaries named the Mae River, Kita River and Tero River, and one routine water quality gauge station for each tributary.

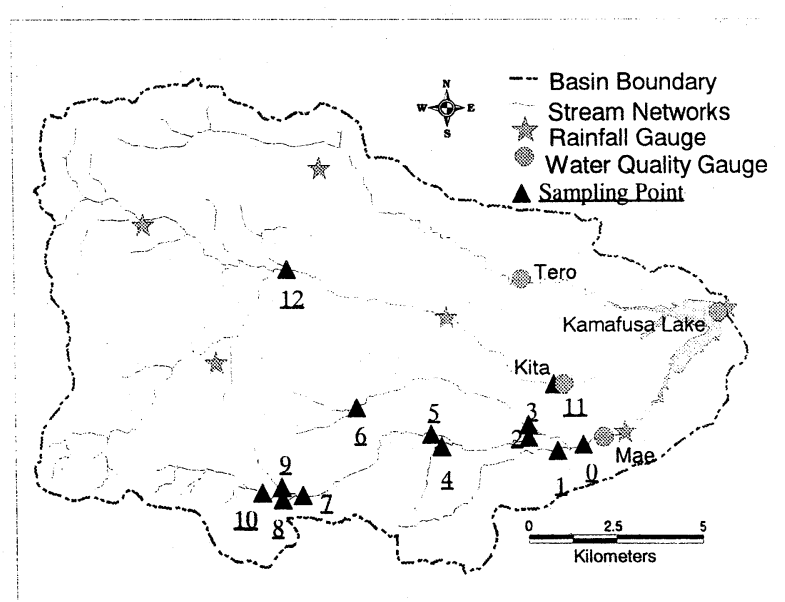

Fig. 1 Study area and sampling points 
Table 1 Landsat TM data with different acquisition date

\begin{tabular}{ccccccccccccc}
\hline Month & 1 & 2 & 3 & 4 & 5 & 6 & 7 & 8 & 10 & 11 & 12 \\
\hline Acquisition & 16 & 22 & 03 & 11 & 27 & 03 & 19 & 15 & 28 & 14 & 26 \\
Date & JAN & FEB & MAR & APR & MAY & JUN & JUL & AUG & OCT & NOV & DEC \\
& 88 & 90 & 99 & 90 & 95 & 92 & 97 & 95 & 93 & 99 & 97 \\
\hline
\end{tabular}

\section{MATERIALS AND METHODS}

\section{(1) Data Description}

Two kinds of water quality data sets were used in this study. One is the routine monitored monthly data at water quality gauge stations of each tributary from 1990 to 1998 , the other is the field survey data set in April 27 and May 25 of 2001 at 13 sampling points as shown in Fig. 1.

Time-series of eleven TM scenes, which ranged from January 16, 1988 to November 14, 1999, were collected and processed to make a time-series NDVI database for each month of one year, except September due to no usable TM scene for this month in all years (Table 1). According to the statistic data of population, land use in this catchment area, there were no large changes from 1990 to $2000{ }^{4)}$. Therefore, it was assumed that there were no significant changes of the vegetation cover in this catchment area between the same month of different years, and the changes were only due to the seasonal variations.

\section{(2) NDVI Database Preparation}

The Landsat TM image were firstly geometrically corrected to Universal Transverse Mercator (UTM) projection, and subset for catchment area only for atmospheric correction and conversion into ground reflectance. Then the NDVI was calculated as follows:

$$
N D V I=\frac{T M 4-T M 3}{T M 4+T M 3}
$$

Where, TM3 and TM4 are ground reflectance of band 3 (Red) and band 4 (infrared).

The calculated NDVI values should fall within the range -1 to +1 , for which positive values are active vegetation and negative values indicate a lack of vegetation. To avoid using the float NDVI values, the NDVI values were scaled to 0 to 200 finally.

\section{a) Clouds, Snow and Water Masking}

Most of sub-scenes used are cloud-free, but three of them, which are used for May, June and August, are covered by some clouds. The presence of clouds is harmful to vegetation detection because they prevent the satellite sensor from detecting the real vegetation information. Before performing the atmospheric correction, the area covered by clouds and their shadows should be masked. Similarly, the snow-covered areas of winter scenes were masked out because of their different spectral characteristics with vegetation cover. The lake area was also masked.

Spectral analyses for each sub-scene were performed so that threshold values of clouds and their shadows, snow covered area and water area for each sub-scene could be found. The areas covered by above features were masked by using of spatial models in ERDAS Imagine based on different thresholds.

\section{b) Atmospheric and Radiometric Correction}

The image-based COST method (COSine of Thetaz, the incidence angle of solar flux) with radiometric calibration was used for atmospheric correction ${ }^{5)}{ }^{6}$. This method is based on general atmospheric correction model (Eq. 2) with some approximations:

$$
R=\frac{P i *\left(L_{\text {sat }}-L_{\text {haze }}\right)}{T A U_{V} *\left(E_{0} * \operatorname{Cos} T Z * T A U_{Z}+E_{\text {down }}\right)}
$$

Where, R-Spectral reflectance of the surface (ground reflectance); $\mathrm{L}_{\text {sat }}$-at-satellite spectral radiance for the given spectral band (W $\mathrm{m}^{-2} \mathrm{sr}^{-1}$ $u^{-1}$ ), which can be converted from raw data (digital number, DN) by using of band-specific calibration coefficients of TM sensor. $\mathrm{L}_{\text {hazc }}$ Upwelling atmospheric spectral radiance scatted in the direction of and at the sensor's field of view. i.e., the path radiance ( $\mathrm{W} \mathrm{m}^{-2} \mathrm{sr}^{-1} \mathrm{um}^{-1}$ ); Band-specific $\mathrm{L}_{\text {haze }}$ value can be derived from the digital image using the dark-object criteria. $\mathrm{TAU}_{\mathrm{v}}$-Atmospheric transmittance along the path from the ground surface to the sensor; TAUv $=\operatorname{Cos}\left(\theta_{v}\right)$, the Cosine of sensor's view angle. In Landsat TM's case, view angle nearly equal to 0 because of the nadir view. $\mathrm{E}_{0}$-Solar spectral irradiance on a surface perpendicular to the Sun's rays outside the atmosphere $\left(\mathrm{W} \mathrm{m}^{-2} \mathrm{um}^{-1}\right) ; \mathrm{E}_{0}$ contains the Earth- 
Sun distance term $\left(\mathrm{d}^{2}\right)$, and $\mathrm{d}$ is in astronomical unit (AU). TZ-Angle of incidence of the direct solar flux onto the Earth's surface(solar zenith angle, $\theta_{z}$ ). $\mathrm{TAU}_{\mathrm{z}}$-Atmospheric transmittance along the path from the Sun to the ground surface; TAUz equals $\operatorname{Cos}\left(\theta_{z}\right)$ for $\operatorname{COST}$ model. $\mathrm{E}_{\mathrm{down}^{-}}$ Downwelling spectral irradiance at the surface due to scattered solar flux in the atmosphere $\left(\mathrm{W} \mathrm{m}^{-2}\right.$ $\left.u^{-1}\right) . E_{\text {down }}$ was ignored in COST method.

By performing the spatial model made under COST method in ERDAS Imagine environment, the raw DN values were converted to atmospherically corrected ground reflectance. And the NDVI values were calculated and scaled. In the following analyses, all the NDVI values shown in figures are scaled-NDVIs.

\section{RESULTS AND DISCUSSION}

\section{(1) Evaluation of TM-based NDVI}

The TM-based NDVI data was compared with 1-km NOAA/AVHRR derived NDVI (Fig. 2). The latter was subset from global land cover database for the Kamafusa catchment. Both of two data sets showed the seasonal variation. In the winter season (December to March), the NDVI values were relatively low, and from the about April, the NDVI values increased with the growing season. The TM-based NDVI showed more precise variation from April to November than 1-km resolution NDVI data set. This made it possible to detect the vegetation changes depending on NDVI variation during this important period.

The maximum TM-based NDVI values were very high and remained no change during one year, and maximum NOAA/AVHRR-based NDVI values showed the differences among different seasons. Although most areas of this catchment are covered with deciduous forest ${ }^{7}$, the field survey showed that there are some evergreen forests distributed in the lower part of catchment. The presence of evergreen forest could explain why the TM-based NDVI had high and nearly constant maximum NDVI values. To the NOAA/AVHRRbased NDVI, it's impossible for AVHRR sensor to detect such kinds of evergreen tree groups because of its lower spatial resolution $(1-\mathrm{km})$, and the NDVI variation detected by AVHRR sensor is due to the dominant deciduous forest in this catchment.

Fig. 3 and 4 plotted the samples of NOAA/AVHRR-based NDVI and TM-based
NDVI respectively. It showed that more precise vegetation cover changes could be detected in small-scale basins by using of TM-based NDVI. The image of Fig. 3 has only $23 \times 17$ pixels, and it's not precise and useless for detecting the vegetation cover changes of study area.

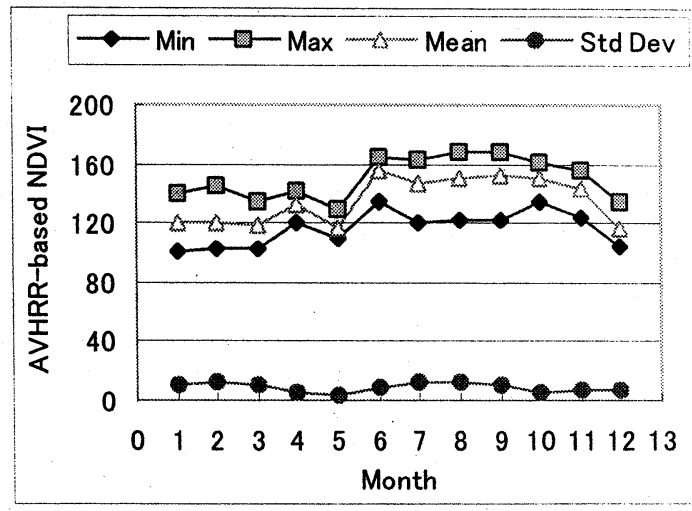

(a) NOAA/AVHRR-based NDVI

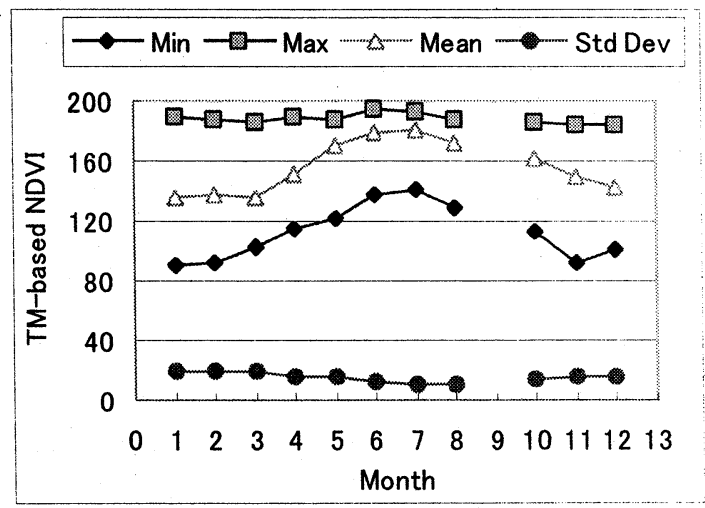

(b) TM-based NDVI

Fig. 2 Comparison of TM-based and AVHRR-based NDVI
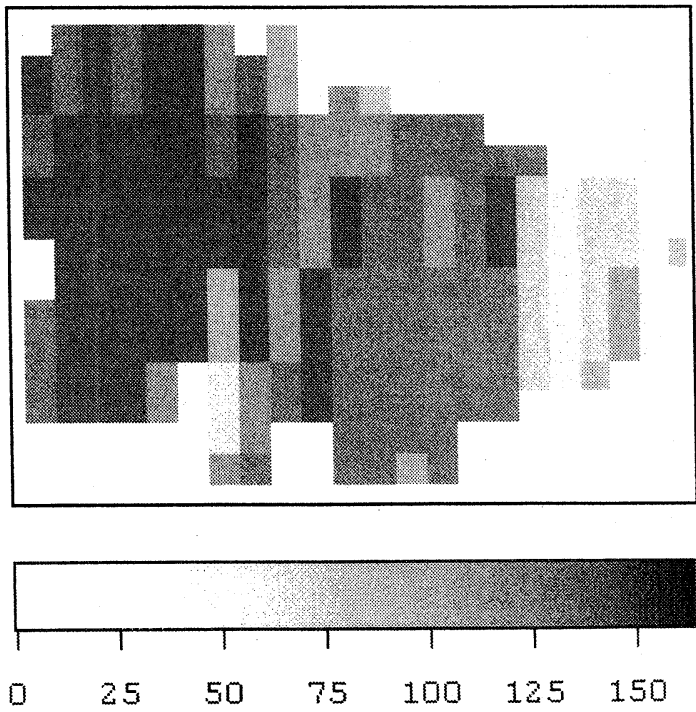

Fig. 3 Grey-Scaled AVHRR-Based NDVI (June, 1992) 


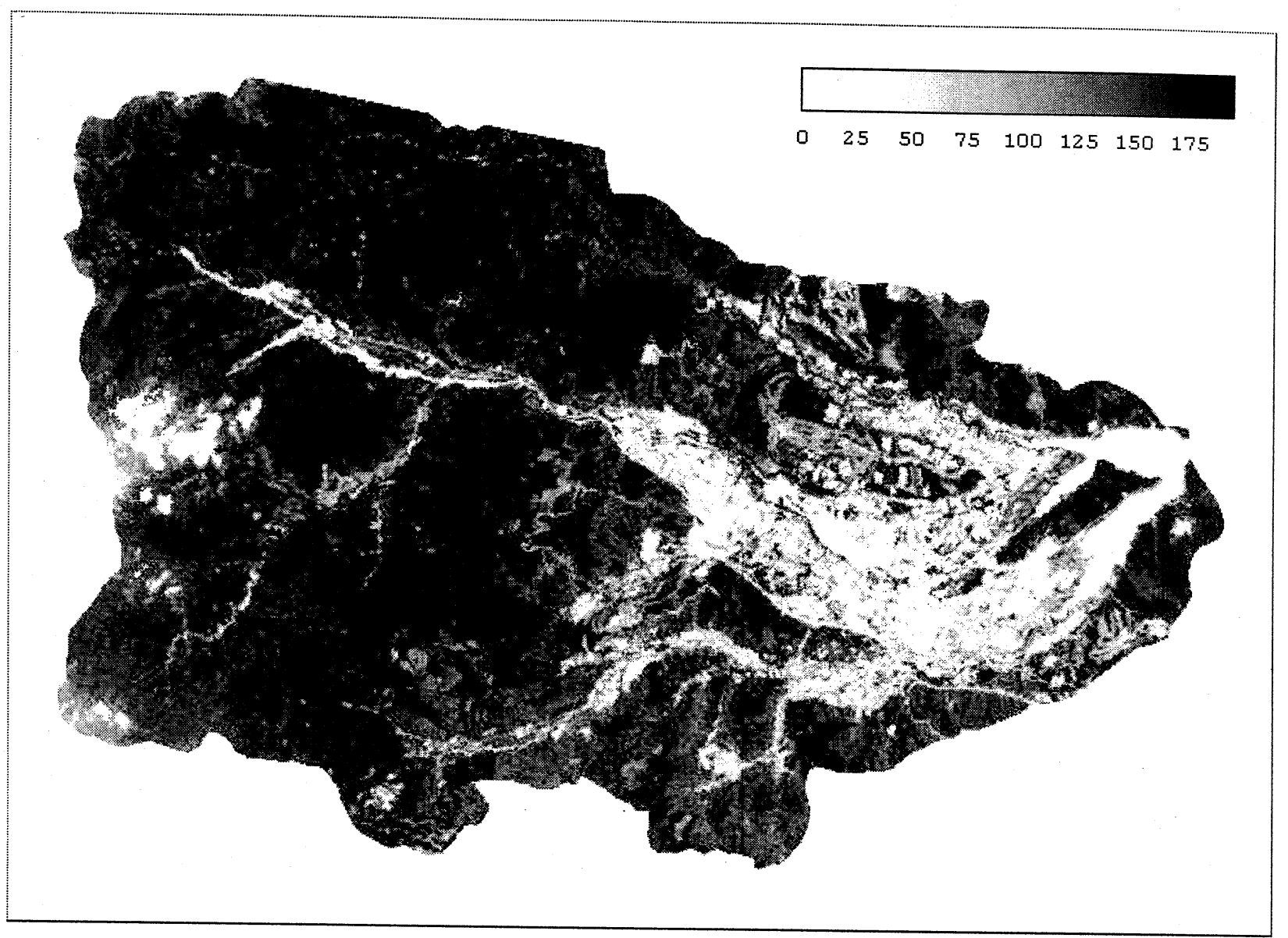

Fig. 4 Grey-Scaled TM-Based NDVI (June $3^{\text {rd }}, 1992$ ) (The lake and clouds covered areas were set to zero)

\section{(2) Calibration of TM-based NDVI}

The NDVI field survey for deciduous forest at the Murata (140 $\left.45^{\prime} 20^{\prime \prime}, 38^{\circ} 10^{\prime} 30^{\prime \prime}\right)$, which is located at the suburb of Sendai City and close to the Kamafusa Lake catchment, were done by Mino during May 1993 to February $1994^{8)}$. All the observations were done in sunny day. Because the Murata is only around $7 \mathrm{~km}$ far from the Kamafusa Lake catchment, this field experiment data can be used to calibrate the COST-based NDVI inside study area.

Fig. 5 showed the observed NDVI of deciduous forest and the mean NDVI of whole catchment. It showed a good agreement between observed NDVI of deciduous forest and mean TM-based NDVI.

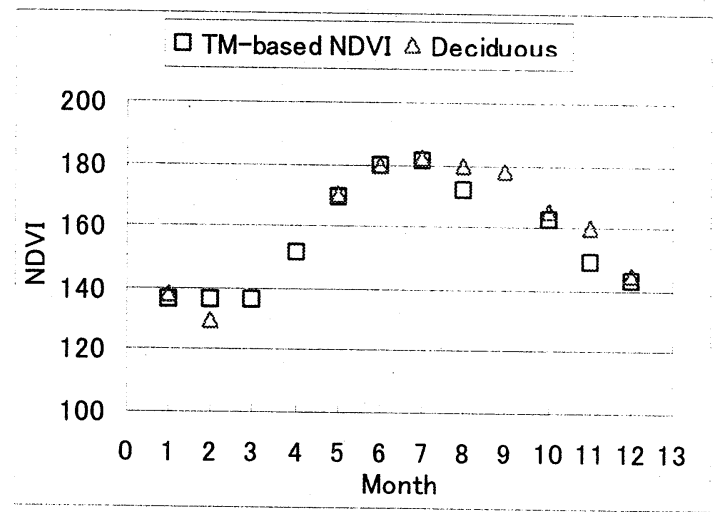

Fig. 5 Observed NDVI of deciduous forest and TM-based NDVI

\section{(3) Relationship among SS, NDVI and Rainfall}

Fig. 6 showed that monthly variation among the monthly mean concentration of Suspended Solids (SS), mean NDVI and monthly mean rainfall in the Mae sub-catchment and the Kita sub-catchment. The monthly mean SS concentration was weighted average concentrations of 9-year SS monitoring data by using the flow rate as the weight, and monthly mean rainfall was the averaged summation of daily rainfalls of each month from 1990 to 1998.

The results showed that the mean NDVI and monthly rainfall increased from May to September, but the SS concentrations did not increase with the rainfall, and their changes were small in the Mae sub-catchment. When the mean NDVI and the monthly rainfall decreased from October to December, the SS concentrations decreased. In the Kita sub-catchment, the variation rule was similar to that in the Mae sub-catchment except in August. In the period from May to September, the dense forest cover, which had high NDVI value, played an important role to prevent SS exporting into stream while raining. Otherwise, the SS concentrations would increase with the increased stream discharge due to the increase of rainfall. In the winter season, 


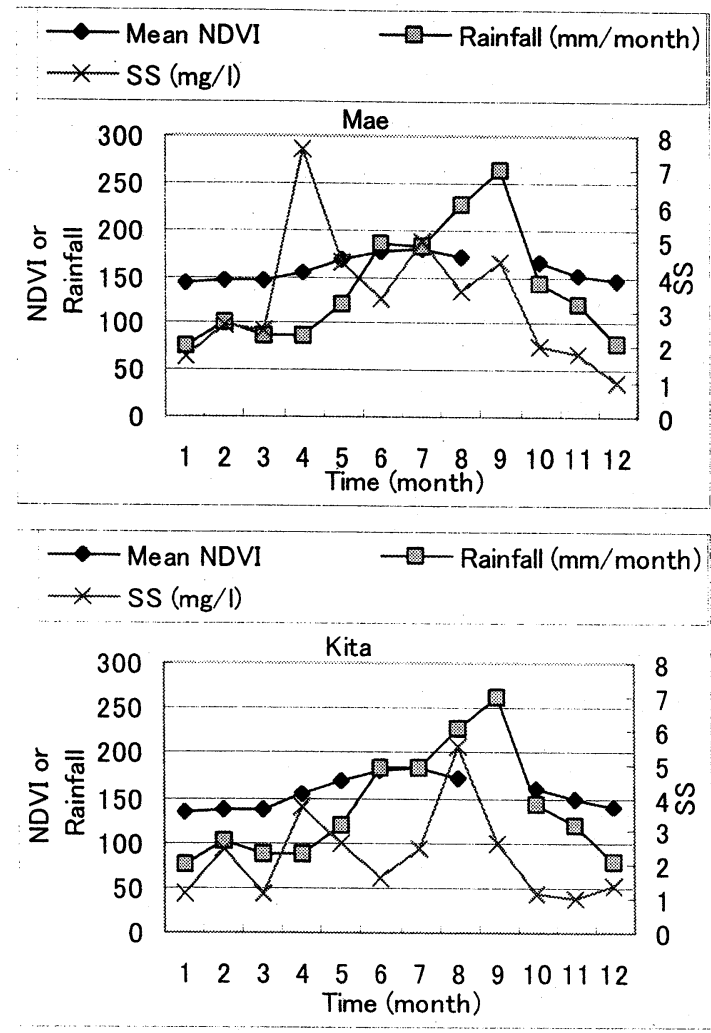

Fig. 6 Relationship among SS, NDVI and rainfall

(Top: Mae sub-area, Bottom: Kita sub-area)

SS concentrations increased from December to March, and reached the maximum value in April, while the monthly rainfall (in winter's case rainfall represented snowfall) did not change so much. This was due to different mechanism. Snowfall cannot generate runoff immediately like what the rainfall does in the rainy season, but it will accumulate in the cold temperature and gradually melt when the temperature increases. This snowmelt process usually reaches its climax in the April (Fig.6). It showed that the snowmelt process played an important role to SS concentration in the snowmelt season. In such period, the NDVI will be helpless in analyzing variation of SS concentration in stream flow with vegetation cover changes, and snowmelt process should be considered because of its dominant effect on the output of SS in the stream water.

\section{(4) Suspended Solids Concentration Changes versus the NDVI}

Depending on the DEM (Digital Elevation Model) data and derived slope data, sub-catchment corresponding to each sampling point (Fig. 1) could be determined by digitizing on the screen along the ridge and valley lines, and main stream networks
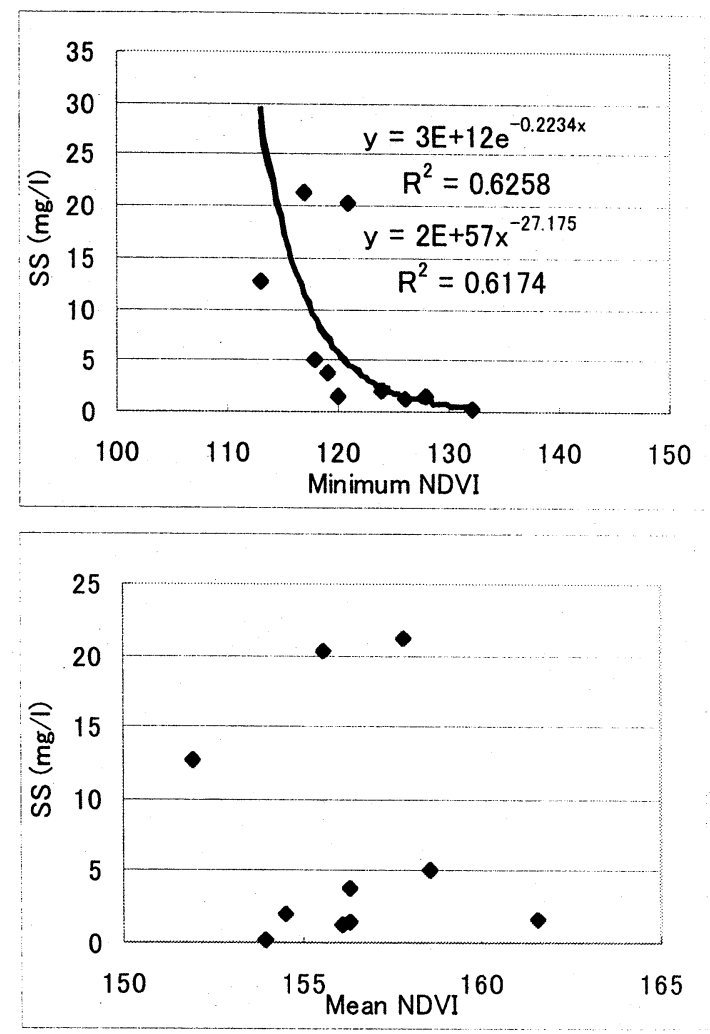

Fig. 7 SS concentration versus NDVI (April)
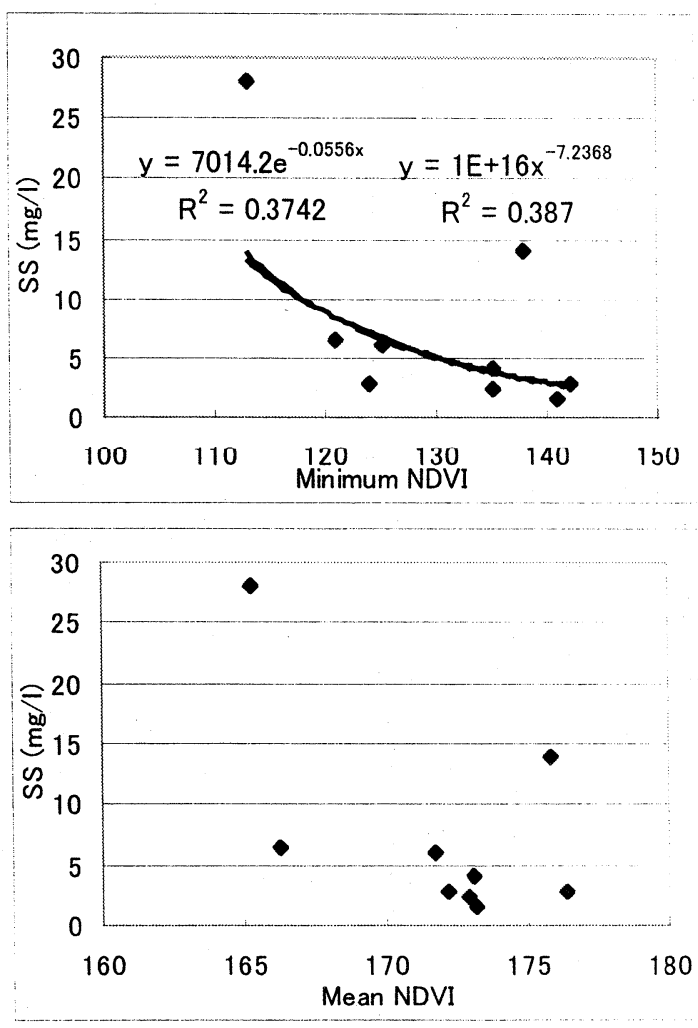

Fig. 8 SS concentration versus NDVI (May)

were used to aid delineation of each small area. The NDVI data inside each sub-area were subset and statistically calculated.

By using the monitored suspended solid (SS) 
and NDVI statistic results for each sub-area corresponding to each sampling point, the relationship of NDVI changes and SS concentration were compared (Figs. 7 and 8). In these figures, the sampling points in the Mae sub-catchment (from point 1 to 10) were considered. The figures showed that SS concentration decreased when minimum NDVI increased, but there was poor correlation with mean NDVI.

As shown in the previous section, the snowmelt process would dominate the output of suspended solids in the April, and the vegetation cover changes had a little effect on the output of SS. In the April case, the SS concentration showed no relation with mean NDVI changes, but it showed relative closer correlation with the minimum NDVI. The lowest NDVI values usually represent such areas where are close to stream networks, such as agricultural land in this season because of less plants in the field. In the May, the situation changed a little. The correlation of SS with minimum NDVI decreased, and correlation between SS and mean NDVI intended to occur. Considering together with the analysis in previous section, it seemed that the dominant role on output of SS would change from snowmelt process in April to rainfall process in May, and the vegetation cover started to play their functions to prevent the SS export during the rainy period.

\section{SUMMARY}

The TM-based NDVI data set showed more precise variation compared with the global AVHRR-based 1-km NDVI data set, and made it possible to detect the vegetation cover changes in small basin area, especially in the non-winter seasons. The correlation between vegetation cover changes and SS export showed that two different mechanisms, i.e., snowmelt process and rainfallrunoff process, should be considered for different season when incorporating the NDVI values to analyze the stream water quality variation.

\section{ACKNOWLEDGMENTS}

The author would like to thank the RESTEC of Japan for their provision of Landsat TM data for research purpose. The author also would like to thank the Sendai Work Office of Ministry of Land, Infrastructure and Transport for their data support. Particularly, Mr. Seiichiro Katayama, Mr. Tadashi Tsunematsu, Mr. Hiroaki Watanabe, Mr. Kyohei Tsuchida and other members in Hydro-Environment System Lab of Civil Engineering Department of Tohoku University are thanked for their kind help in the field survey.

\section{REFERENCES}

1. Brown, J.F., Loveland, T.R., Ohlen, D.O., Zhu, Z., (1999). The Global Land-Cover Characteristics Database: The Users' Perspective. Photogrammetric Engineering and Remote Sensing, v. 65, no. 9, p. 1,069-1,074.

2. Scepan, J., (1999). Thematic Validation of High-Resolution Global Land-Cover Data Sets, Photogrammetric Engineering and Remote Sensing, v. 65, no. 9, p. 1051-1060.

3. Brown, J.F., Loveland, T.R., Ohlen, D.O., Zhu, Z., (1999). The Global Land-Cover Characteristics Database: The Users' Perspective. Photogrammetric Engineering and Remote Sensing, v. 65, no. 9, p. 1,069-1,074.

4. Miyagi Prefecture, Statistics Yearbook of Miyagi, Japan, 1989-2000 (in Japanese).

5. Chavez, P.S., Jr., (1996), Image-based atmospheric corrections-revisited and revised. Photogrammetric Engineering and Remote Sensing 62(9):1025-1036.

6. Moran, M.S., R.D. Jackson, P.N. Slater, and P.M. Teillet, (1992), Evaluation of simplified procedures for retrieval of land surface reflectance factors from satellite sensor output. Remote Sensing of Environment 41:169-184.

7. Tsutsumi, Toshio, (1989), Forest Ecology, book, pp 2-4 (in Japanese)

8. Mino, K., (1994), Development of Macro Environment Assessment Approach Using Satellite Data, Master Thesis, Tohoku University.

(Received October 1, 2001) 